\title{
Determination of parameters of mathematical model of quality assessment of surface waste treatment in urbanized territories
}

\author{
Ekaterina Davydova ${ }^{1 *}$, Arkadiy $\mathrm{Kim}^{2}$, and Alfiya Kapizova ${ }^{1}$ \\ ${ }^{1}$ Astrakhan State University of Architecture and Civil Engineering, Civil building department, \\ 414056, 18 Tatishcheva str., Astrakhan, Russia \\ ${ }^{2}$ Saint-Petersburg state university of architecture and civil engineering, 190005, 4 2-ya \\ Krasnoarmeiskaya St., Saint-Petersburg, Russia
}

\begin{abstract}
The publication presents the results of an analysis of the dynamics of changes in surface water quality in the Lower Volga basin based on the processing of statistical data on monitoring the degree of pollution over a long period. Significant all-season excesses of the maximum permissible norms for the concentration in water of a whole spectrum of background and anthropogenic pollutants were recorded. Deficiencies in the implementation of existing methods have been identified that make it possible to assess the dynamics of changes in the state of the ecosystem of the water basin and select the most significant parameters for constructing a mathematical model for choosing the most effective wastewater treatment technology. The aim of this work is to select and evaluate the input parameters of a mathematical model, the implementation of which will ensure the search for optimal technology and appropriate technical means of surface wastewater treatment. This research is based on a comprehensive assessment of a wide range of hydrochemical indicators of pollution of discharged wastewater in controlled sites using statistical methods for processing observational data. The most significant parameters have been identified that allow the formation of a conceptual model, and the degree of their influence on the selection of optimal means and methods of wastewater treatment has been determined.
\end{abstract}

\section{Introduction}

The level of the ecological state of water resources in most of the territory of the Russian Federation is approaching a critical level. One of the main reasons is the increase in the flow of polluting anthropogenic substances to surface sources with the extremely low efficiency of treatment facilities caused by the use of outdated technologies and technical means. Thus, according to generalized statistical data for the Russian Federation, an average of 52 cubic kilometers of wastewater is discharged into water bodies annually, with about 20 cubic kilometers of which being treated and only $10 \%$ of them comply with

\footnotetext{
*Corresponding author: katya_11_05@mail.ru
} 
established quality standards. The remaining part of the total volume is discharged either insufficiently cleaned or completely without cleaning. [1].

The quality of surface runoff is determined by many simultaneously acting factors that can affect the sanitary condition and factors that affect the speed and meaning of the accumulated resources. pollution.

Weighing in the form of particles in the form of particles of water in the form of particles of more than 100 microns and in the form of particles of a thin suspension or emulsion with a particle size of $100-0.1$ microns. Colloidal substances in wastewater have a particle size of $0.1-0.001$ microns.

Petroleum products are among the most dangerous organic pollution of water bodies. Having low solubility in water, they decompose naturally in an extremely slow manner. Having a low density, oil products (even at a low concentration) form a film on the water surface that prevents the dissolution of atmospheric oxygen in water. Petroleum products have a direct toxic effect on aquatic organisms: they clog the cell membranes through which all metabolic processes are carried out.

The concentration of the main impurities in the rain runoff is the higher, the smaller the precipitation layer and the longer the period of dry weather, and changes during the rainwater runoff. The highest concentrations occur at the beginning of the runoff until the maximum flow rate is reached, after which their intensive decrease is observed.

The concentration of impurities in melt water depends on the amount of precipitation falling in the cold season, the proportion of soil surfaces in the balance of the flow area and the influx of melt water from adjacent undeveloped areas.

To solve the issue of surface runoff cleaning, it is very important today to choose the most effective and economically feasible treatment technology based on data on the volume of surface runoff and its pollution.

Thus, one of the priorities of modern science and society is the need to preserve the ecosystem of the water basin for the possibility of reproduction and maintenance of the biological diversity of natural resources, as well as providing the population with clean water [1-4].

\subsection{Literature review}

Numerous works by scientists are devoted to the solution of the problem of the formulated problem: P. F. Gorbachev, N. N. Belova, M. I. Alekseev, A. N. Kim, A. M. Kurganov, V. I. Kichigin, V. S. Dikarevsky, V. L. Karagodin, M. V. Molokov, A. V. Mikhailova, N.S. Serpokrylova, M.G. Zhurba, Wach Betoll Verh, Campbell, Hall, Pocarhevskii, Ben Souissi Jamila I.S. Schukin and others.

In the course of the presented studies, significant amounts of experimental data have been accumulated. Difficulties arise at the stage of their processing and generalization in the mathematical modeling of the dynamics of changes in the state of ecosystems by the time factor.

Currently existing models have a number of disadvantages such as extrapolation of forecast estimates in some cases is difficult, although the interpolation of the initial data is performed with the required accuracy; information in a specific control point must be collected in a relatively short time by a single method; assessment of qualitative indicators essential to justify changes in the state of the object of study, if possible, it is extremely subjective.

The identified shortcomings indicate the need to improve the means and methods of forecasting the development of the situation in the future. In order to create a systematic approach to choosing the most effective flowsheet and related technical means of water treatment group of scientists Comprehensive research, design and technology Institute of 
water supply, Sewerage, hydraulic structures and engineering hydrogeology. The results presented by them in the form of summary tables are of interest from the point of view of generalization of the accumulated knowledge and experience on definition of means and methods of water purification depending on presence in it of specific types of pollutants. However, this classifier is considered by the authors of the article only as a source of formation and filling of the database. The decision on the choice of optimal technology and appropriate technical means of surface wastewater treatment is possible on the basis of the results of the mathematical model. The degree of water purification and filtration rate were determined as control criteria for its construction[2-8].

\section{Materials and methods}

To assess the input parameters of the model, in the course of the present study, water quality was monitored in the lower reaches of the Volga River and its branches located in the territory of the Astrakhan Region. The choice of survey objects is due to the fact that with coverage of only $8 \%$ of the total area of the Russian Federation from adjacent territories, more than $45 \%$ of all industrial and $50 \%$ of agricultural enterprises of the country are discharged into the Volga basin. The toxic load on the ecosystem is aggravated by the volume of pollution of public utilities and storm drains of 442 cities [4, 7, 19, 21].

Geographically, the floodplain and delta zones of the basin are located in the Caspian lowland, forming a large "sewage pit" (fig. 1) of pollution accumulation over the entire spectrum of elements of the periodic table [7]. Despite the physicochemical and biological processes, as well as polymerization processes, leading to partial self-purification of water and a decrease in the migration ability of pollutants, the maximum presence of toxic compounds is recorded in the arms of the river mouth.

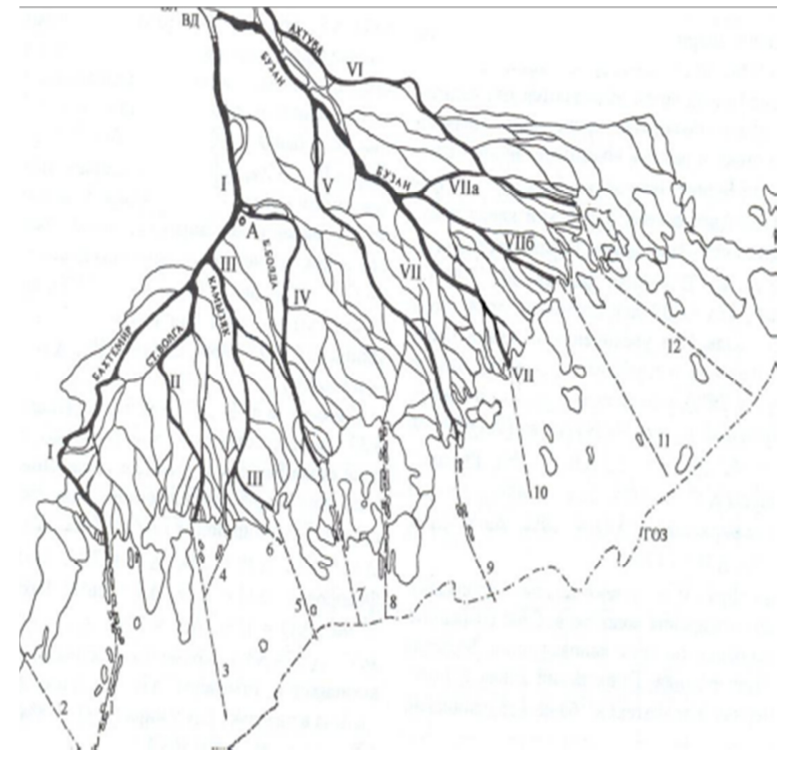

I - Volga-Bakhtemir; II - Old river-sauna and BBQ-Gandurinski the Bank; III - Kamyzyak-ryty Bank; IV-Bolshaya BoldaBolshaya Chernaya-Tabola-Karalatsky Bank; V- Buzan-Smagino-Step-Bushma-Belinskiy Bank; VI - Akhtuba - the Kigach Summize; VII-Buzan-Churka-Sarbay-Anastasieva-Fomin Bank - Karaysky Bank; Vip-Buzan-Tyurina-Sumnitsa-Igolkinsky Bank; VII b-Buzan -Gluttonous Bank. The main channels in the shallow zone of the estuary: 1-Volga-Caspian (VC); 2 - Lagansky; 3Gandurinsky; 4-Nikitinsky; 5-Kirovsky; 6-Kulaginsky; 7 - Bardyninsky; 8-Tishkovsky; 9-Belinsky; 10-Karaysky; 11Obzhorovsky; 12 - Igolkinsky. A-Astrakhan; VL-S. Upper Lebyazhye; b-top of the Delta; state border shallow zones of estuarine seashore.

Fig. 1. Scheme of the Volga river Delta. 
In connection with the large extent of the basin in the lower reaches of the Volga River and the multiplicity of its branches in the delta zone, it was segmented. Analysis of statistical information was carried out based on observational data for 11 posts of the Astrakhan Regional Center for Hydrometeorology and Environmental Monitoring, distributed over the Volga channel and sections of its large arms $[6,8,9]$. The results of the study indicate significant seasonal fluctuations in the concentration of pollutants in the water, the cause of which is a change in hydrological regimes. However, the selected ranges of variation for many indicators of the content of impurities having both background and anthropogenic nature of formation do not fit into the normative framework of maximum permissible concentrations of harmful substances defined for surface waters of fishery water use (table 1) [11].

Table 1. Numerical statistical characteristics of the distribution of seasonal concentrations of pollutants in the waters of the Lower Volga basin.

\begin{tabular}{|c|c|c|c|c|c|}
\hline \multirow{2}{*}{$\begin{array}{c}\text { Name of } \\
\text { pollutant }\end{array}$} & $\bar{X}, \mathrm{mg} / \mathrm{l}$ & $\sigma, \mathrm{mg} / \mathrm{l}$ & $\operatorname{Var}(x)$ & Range of variation, mg/l & $\begin{array}{c}\text { Maximum } \\
\text { Allowable } \\
\text { Concentration, } \\
\mathrm{mg} / \mathrm{l}\end{array}$ \\
\cline { 2 - 6 } $\begin{array}{c}\text { Synthetic } \\
\text { Surfactants }\end{array}$ & 0,026 & 0,007 & $28 \%$ & {$[0,019 ; 0,033]$} & 0,1 \\
\hline oil products & 0,201 & 0,054 & $27 \%$ & {$[0,147 ; 0,255]$} & 0,05 \\
\hline phenols & 0,0039 & 0,0008 & $22 \%$ & {$[0,0031 ; 0,0047]$} & 0,001 \\
\hline zinc & 0,035 & 0,004 & $11 \%$ & {$[0,031 ; 0,039]$} & 0,01 \\
\hline copper & 0,0064 & 0,0017 & $27 \%$ & {$[0,0047 ; 0,0081]$} & 0,001 \\
\hline common \\
iron
\end{tabular}

When searching for ranges of concentration of pollutants, the results of observations for the period 2006-2015 were used [12]. An analysis of a sample of data on the degree of presence of each of the harmful components in water samples was carried out based on such numerical statistical characteristics. The analysis also assessed the change in the volume of accumulation of pollutants in the Volga estuary over the same period based on the average annual growth rate. Its value is the geometric mean of chain growth coefficients and shows how many times on average per year the concentration of impurities changes in relation to the same indicator for the previous period (fig. 2). 


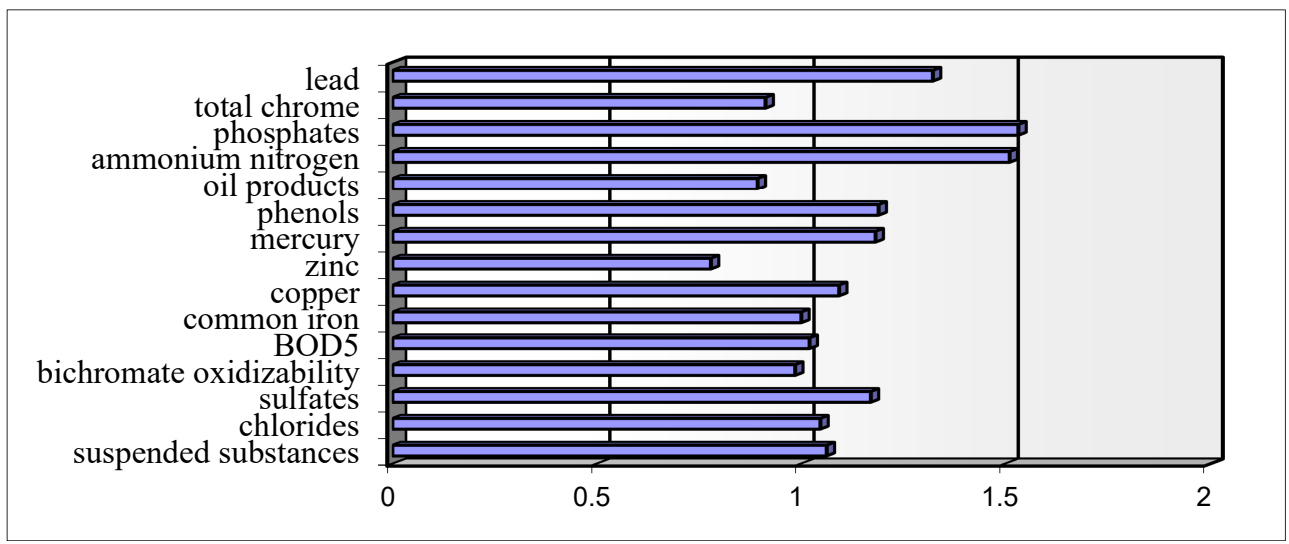

Fig. 2. Average annual growth rates of pollutant concentrations in the surface waters of the lower Volga basin for the period 2006-2015.

The graphical interpretation of the average annual growth factors presented in the figure allows us to conclude that there is an unfavorable dynamics for an increase in a separate group of harmful substances in water samples [14, 22]. This group should include lead, phosphates, ammonium nitrogen, phenols, mercury, sulfates, the considered indicator for which significantly exceeds 1 . So, for example, a value of $\bar{K}_{p} \approx 1,3$ for lead indicates that the concentration of this substance in water samples from 2006 to 2015 on average per year increases by 1.3 times, forming a geometric progression of the levels of the time series of dynamics.

As one of the main factors determining the dynamics identified for the deterioration of the environmental situation of the water objects of the delta zone of the Volga basin, there is an increase in the volume of discharge of surface wastewater untreated to the required standards from adjacent residential areas and production sites along the entire river channel $[13,22]$. By analyzing the structure of wastewater discharged according to state reports on the environmental situation in the territory of the Astrakhan region for 2008-2014 [12], the proportion of insufficiently treated wastewater in the total volume for this period increased from $14 \%$ to $16.4 \%$. Mostly this fact is due to a decrease in the efficiency of treatment facilities of housing and communal services enterprises built in the first half of the last century. As for storm and drainage waters, to this day they are discharged into the Volga without any treatment $[7,17]$.

\section{Research results}

In the course of the research, the authors of the article conducted tests to collect water samples from storm sewer wells located along the central streets of the city of Astrakhan. Samples obtained in the warm season are analyzed for the presence of contaminating substances in them. The processing of the results is reduced to establishing the frequency of exceeding the maximum permissible concentrations of each of the identified pollutants in the experimental samples. Table 2 presents sample data for some of them.

The results obtained demonstrate multiple excesses of normative values for surface waters of fishery water use in the vast majority of positions. Even taking into account that due to the climatic conditions of the Astrakhan region, the volume of storm and drainage water discharge does not exceed $0.32 \%$ of the total volume of wastewater entering the water body, it significantly increases the toxic load on the ecosystem. This is explained by the fact that the discharge without treatment of 1 cubic meter of such water leads to pollution to the limit values of standards of more than 100 cubic meters of absolutely pure 
water. If we take into account the already significant pollution of the water source (see table. 1), then the corresponding effect is amplified many times.

Table 2. The average rate of exceeding the MPC for the content of pollutants in water samples of street storm sewers in Astrakhan.

\begin{tabular}{|c|c|c|c|c|c|c|}
\hline \multirow{2}{*}{ Indicators } & \multicolumn{5}{|c|}{ Test results } & \multirow{2}{*}{$\begin{array}{c}\text { Average } \\
\text { value }\end{array}$} \\
\cline { 2 - 6 } ammonium ions & 51 & 147 & 34 & 62 & 77 & 74 \\
\hline BOD & 101 & 170 & 125 & 164 & 162 & 144 \\
\hline weighted & 493 & 1892 & 1280 & 2193 & 3659 & 1903 \\
\hline pH & 1,05 & 1,14 & 1,22 & 1,22 & 1,2 & 1,17 \\
\hline common iron & 74 & 107 & 99 & 123 & 163 & 113 \\
\hline permanganate & 4,3 & 6,4 & 8,7 & 8,5 & 4,5 & 6,5 \\
\hline oxidizability & 0,25 & 0,36 & 2,02 & 1,88 & 0,6 & 1,02 \\
\hline sulfates & 42 & 64 & 42 & 64 & 12 & 45 \\
\hline phenols & 0,18 & 0,41 & 0,62 & 0,56 & 0,47 & 0,45 \\
\hline chlorides & 70 & 72 & 56 & 55 & 42 & 59 \\
\hline copper & 42 & 68 & 48 & 63 & 122 & 69 \\
\hline COD & 23 & 51 & 19 & 21 & 33 & 29 \\
\hline zinc & 5 & 6,7 & 4,3 & 5,3 & 3,3 & 4,9 \\
\hline lead & 0,19 & 0,29 & 0,13 & 0,11 & 0,14 & 0,17 \\
\hline chromium & 8 & 12 & 11 & 10 & 12 & 11 \\
\hline manganese & 75 & 130 & 114 & 101 & 91 & 102 \\
\hline oil products & & & & & \\
\hline
\end{tabular}

The results obtained demonstrate multiple excesses of normative values for surface waters of fishery water use in the vast majority of positions. Even taking into account that due to the climatic conditions of the Astrakhan region, the volume of storm and drainage water discharge does not exceed $0.32 \%$ of the total volume of wastewater entering the water body, it significantly increases the toxic load on the ecosystem. This is explained by the fact that the discharge without treatment of 1 cubic meter of such water leads to pollution to the limit values of standards of more than 100 cubic meters of absolutely pure water. If we take into account the already significant pollution of the water source (see table. 1), then the corresponding effect is amplified many times.

\section{Conclusions}

Thus, as the most significant input parameters of the conceptual model for the selection of the most effective technology and technical means for treating surface wastewater:

1. group of wastewater according to the classification (domestic, industrial, agricultural, atmospheric),

2. spillway source class

3. factors and volumes of anthropogenic impact,

4. phase dispersed state of impurities 
The establishment of a functional relationship between the listed parameters should be presented as an optimization problem when choosing the degree of water purification and its filtration rate as control criteria.

\section{Reference}

1. L. Boronina, P. Sadchikov, S. Tazhieva, A. Usynina, E. Moskvichiova, Effect. Automat. Select. Wat. Treatm. Technol. Partic. Wat. Source, Advan. Mater. Res. 1073-1076, 1039-1042 (2014)

2. M. A. Yurechko, O.M. Shikulskaya, Biotechnosphere 3 (33), 69-71 (2014)

3. O. Shikulskaya, L. Boronina, M. Yurechko, I. Petrova, M. Shikulskiy, Cognitive analysis of the heavy metals influence on the aquatic ecosystem," in Information, Intelligence, Systems, and Applications (IISA), 2015 6th International Conference, 1-5 (2015)

4. L.V. Boronina, P.N. Sadchikov, S.Z. Tazhieva, E.V. Moskvicheva, Wat. Resour., 43(4), 419-425 (2017)

5. L.V Boronina, G.B Abuova, T.F Ryltseva, G.L Gizzatova, Yu.N Gonchar, V.P. Batmanov, Bull. Volgog. St. Un. Archit. Civil Engin. Ser.: Construc. Architec. 32 (51), 116121 (2013)

6. A.N. Kim, E.V Davydova, D.I Polyanskaya, Urban plan. Architect. 2(23), 31-35 (2016)

7. L. V. Boronina, P. N. Sadchikov, Wat. Sup. San. Equip. 11, 15-21 (2012)

8. L. V. Boronina, P. N. Sadchikov S.Z. Tazhieva, A.E Usynina, Engin. Constr. Bull. Casp. Sea, 1(7), 66-71 (2014)

9. M. T. Bryk, R. R. Nigmatulin, Chem. Wat. Technol. 17(4), 395-396 (1995)

10. N. Zwart, W. Jonker, R. Broek, J. de Boer, M. H. Lamoree, Wat. Res. J. Available online 16 October 2019, Article 115204.

11. R. Verma, S. Suthar, Ecol. Engin. 116, 121-126

12. N. N. Zhukov, Wat. Sup. San. Equip., 1,10-13 (2000)

13. V. I. Kichigin, Modeling of water purification processes: textbook. Manual for universities, (2002)

14. K. Thirugnanasambandham, V. Sivakumar, M.J. Prakash, Tai. Inst. Chem. Engin. 46, 160-167, (2015)

15. A.A., Sizov, N.S., Serpokrylov, Y.Yu. Kamenev, Bull.of SASAS. Urban plan. Architect. 4 (8), 71-74 (2012)

16. A. A. Prata, J. M. Santos, V. Timchenko, R. M. Stuetz, Wat. Res. 130, 388-406 (2018)

17. A.B. Mikhailov, Reports of international scientific practice Symposium "Gulf of Finland 96", 102-103 (1996)

18. A.K., Strelkov A.K., M.A., Gridneva M.A., Nabok T.Yu., Dremina E.V., E.E. Kondrina, Bull. of SASU. Urban plan. Architect. 4(17), (2014)

19. Y. Yang, Z. Zhou, C. Lu, Y. Chen, C. Cheng, J. Envir. Manag. 198, 12-20 (2017) 